\title{
Integrating Tinbergen's inquiries: Mimicry and play in humans and other social mammals
}

\author{
Elisabetta Palagi ${ }^{1} \cdot$ Chiara Scopa $^{1}$
}

Published online: 21 June 2017

(C) Psychonomic Society, Inc. 2017

\begin{abstract}
Visual signals convey emotions and intentions between individuals. Darwin underlined that human facial expressions represent a shared heritage between our species and many other social mammals. Social play is a fertile field to examine the role and the potential communicative function of facial expressions. The relaxed open-mouth (or play face) is a context-specific playful expression, which is widespread in human and non-human mammals. Here, we focus on playful communication by applying Tinbergen's four areas of inquiry: proximate causation, ontogeny, function, and evolution. First of all we explore mimicry by focusing on its neural substrates and factors of modulation within playful and non-playful context (proximate causation). Play face is one of the earliest facial expressions to appear and be mimicked in neonates. The motor resonance between infants and their caregivers is essential later in life when individuals begin to engage in increasingly complex social interactions, including play (ontogeny). The success of a playful session can be evaluated by its duration in time. Mirroring facial expressions prolongs the session by favoring individuals to fine-tune their own motor sequences accordingly (function). Finally, through a comparative approach we also demonstrate that the elements constituting play communication and mimicry are sensitive to the quality of interindividual relationships of a species, thus reflecting the nature of its social network and style (evolution). In conclusion, our goal is to integrate Tinbergen's four areas of
\end{abstract}

Elisabetta Palagi

elisabetta.palagi@unipi.it

Chiara Scopa

chiara.scopa@gmail.com

1 Natural History Museum, University of Pisa, Via Roma 79, 56011 Calci, Pisa, Italy ethological inquiry to provide a broader framework regarding the importance of communication and mimicry in the play domain of humans and other social mammals.

Keywords Emotional contagion - Ethological perspective · Seals $\cdot$ Dogs $\cdot$ Monkeys $\cdot$ Apes $\cdot$ Homo sapiens

\section{Introduction}

Behavioral mimicry is virtually present in any kind of social interaction, occurring both as a simple behavioral/motor resonance and as a more sophisticated mechanism by which an individual can experience another's affective state (Duffy \& Chartrand, 2015). Nowadays, many researchers are challenged to find the most suitable experimental condition or the best setting to unveil mimicry phenomena. As soon as one starts to analyze the causation of the components concurring in activating a multi-faced phenomenon, it appears clear that such components may not only be inter-linked, but also associated with other processes that can be totally dissimilar and apparently detached from the phenomenon itself (Diversity organizes unity which organizes, Morin, 1977). Tinbergen (1963) used this reasoning in his magnum opus about aims and methods on ethology. In his paper, Tinbergen underlines the importance of an integrative overview coming from neurophysiology and ethology. While neurophysiologists tended to investigate proximate causations of any phenomenon by applying an "ascending" approach, the ethologists tended to apply a "descending" approach by dissembling the phenomenon in several building-blocks. In his work, Tinbergen states that "no-man's land between ethology and neurophysiology is being invaded from both sides' and that a rapprochement was occurring between neurophysiologists that were studying gradually more and more complex 
phenomena and ethologists that were doing gradually more focused research so that was becoming difficult to say 'where ethology stops and neurophysiology begins."

Starting from the top of this conceptual iceberg, ethologists investigate the nature of a phenomenon in terms of the systematic description of specific environmental circumstances that can affect the behavior under study. This cause-effect linkage is explored in each developmental stage of the life history of an individual (ontogeny). For this reason, following the ontogenetic pathways of any phenomenon characterizing the adult phase can unveil the process thereby and the reason why a particular behavioral pattern appears early in life to be modified or optimized later in adulthood. As for mimicry, tracing back to its first developmental manifestations is imperative to identify the evolutionary selective pressures that it underwent and, more importantly, the potential functions that mimicry has in so many different species. Following Tinbergen's rationale, the survival values are another keypoint of the ethological investigation of a behavior. Mimicry finds its complete expression in the play domain, a ubiquitous, plastic, and positive-emotional behavior (Burghardt, 2005). Ethologists, sociobiologists, and anthropologists defined play as all activity, which has no immediate benefits and which involves motor patterns, typical of serious contexts. Burghardt (2005) listed several criteria to define a playful motor action. A playful pattern must be incompletely functional, autotelic, structurally or temporally modified, and repetitive. The synchronization occurring between players passes through their motor resonance thus creating a positive feedback loop that promotes and reinforces social affiliation. In this perspective, mimicry is not only the mere perception and replication of a motor sequence, but rather an unconscious mechanism favoring the formation of inter-individual emotional bridges (function).

Tinbergen (1963, p. 428) stated that "the first task... [of evolutionary studies]... is being pursued mainly through comparison of groups of closely related species." Here, we also extended Tinbergen's comparative lens to culturally similar human societies. After a meticulous comparison of how mimicry is socially modulated in several non-human mammal species and in different human societies, what appears clear is that both laboratory and naturalistic approaches are essential to reliably understand which are the evolutionary foundations of mimicry.

This review aims at putting together different pieces of the same puzzle in order to gain a new viewpoint on mimicry by giving an integrated interpretation of the information available in the literature and of some original data.

For the sake of writing convenience, we kept the four areas of inquiries separated in different paragraphs. However, the reader will find in each paragraph continuous references to the others due to the impossibility to conceptually disentangle the four inquiries in order to obtain a valid holistic framework regarding the mimicry phenomenon.

\section{Proximate causes of mimicry: The neural bases and modulating factors}

With the term mimicry we refer to the unconscious and unintentional imitation of behavior shown by two interacting partners (Hess \& Fischer, 2013). The "true" imitation occurs when the observer both recognizes the goal of the demonstrator and reaches that goal by exactly copying the sequence of actions made by the demonstrator (Call \& Tomasello, 1995; Whiten et al., 2009). The exact reproduction of hand movements operated by infant chimpanzees while observing the motor hand-patterns made by their mothers during nut cracking is an example of true imitation sensu Tomasello and coworkers (1993). When the copying action does not involve any recognition of the goal, the "imitative" phenomenon is called mimicry (Tomasello et al., 1993).

From an operational point of view, facial mimicry implies the activation of a congruent facial expression in response to the mere observation of another's facial expression (Seibt et al., 2015). The mimicry response is quantifiable by measuring the recruitment of facial muscles whose activation determines a specific facial expression. The same facial muscle involvement produces the same facial expression in the two interacting individuals. Changes in muscle recruitment are measured as the difference between the reaction score (the muscle activity while watching the expression) and the baseline (the muscle activity during the second before the onset of the stimulus). Given that the muscle reaction begins within the first $500 \mathrm{~ms}$ after the perception of the stimulus, the extremely rapid reaction time indicates that mimicry is outside of conscious awareness and of voluntary control, at least in part (Dimberg \& Thunberg, 1998). Therefore, facial/body rapid mimicry can be defined as a reflex reaction (Seibt et al., 2015). Since rapid mimicry is far from being a mere motor replication of muscle movements, in the last decades it has been the subject of many studies regarding human and nonhuman mammals with its social function and evolution being revaluated (Hecht et al., 2012).

One of the neurological substrates at the basis of the mechanism of imitative processes is the Mirror Neuron System (MNS). Mirror neurons, located in the prefrontal cortex, fire not only when a subject enacts a motor action but also when he/she watches the same action performed by others (di Pellegrino et al., 1992; Gallese et al., 1996; Parr et al., 2005; Rizzolatti et al., 1996a,b). MNS contributes differently to different forms of imitation. MNS can act in concert with other cortical structures through an "indirect pathway" thus producing delayed responses (true imitation, Thorpe, 1963; Tomasello \& Call, 1997; response facilitation, Byrne, 1994; emulation, Nagell et al., 1993; delayed mimicry, Davila-Ross et al., 2011) and it can also directly influence the motor outcome through a "direct pathway" as it occurs in very fast responses such as rapid mimicry (Davila-Ross et al., 2008; 
Ferrari et al., 2009; Hess \& Fischer, 2013; Mancini et al., 2013a).

When dealing with neurological processes underlying automatic mimicry, comparative psychologists refer to the perception-action mechanism to describe the phenomenon (Preston \& de Waal, 2002). The perception-action model states that the perception of the emotional state of others involuntarily produces a corresponding state in the receiver, which in turn stimulates the corresponding somatic and unconscious responses (Preston \& Waal, 2002). This leads the two interactans to share not only the same facial expression (facial mimicry) but also the same emotion (emotional mimicry) (Dezecache et al., 2015; Gallese et al., 2004; Hatfield et al., 1994). Several authors referred to this phenomenon as "primitive emotional contagion" (Flack, 2006; Stepper \& Strack, 1993).

Mimicry, however, is not an all-or-nothing process, but it is socially, context, and previous-experience modulated. As for previous experience, Murata et al. (2016) found that facial mimicry responsiveness increased when the human subjects were given the explicit goal of inferring the affective states of triggers. The awareness of the goal promoted the promptness of the tested subjects to anticipate (consciously or unconsciously) the emotional expression, thus improving the facial mimicry response. Facial mimicry seems also to be shaped by the reputation for fairness of the subjects involved (Hofman et al., 2012).

In humans facial mimicry is affected by socio-ecological factors, including group membership (Seibt et al., 2015). People tend to mimic the facial expressions of in-group members more than those of out-group members. This is extremely adaptive from an evolutionary point of view (evolution). Decoding in an appropriate way the in-group members' emotional states is more important than experiencing the emotional state of out-group members, with whom we share few resources and little or no social contact (Bourgeois \& Hesse, 2008).

The frequency of rapid matching response is also strongly affected by the level of bonding shared between the two subjects who are interacting. Among in-group members, two friends usually engage in a higher level of mimicry compared to weakly bonded group members. At the same time, the automatic tendency to mimic increases the feeling of similarity and understanding between different subjects, thus fostering prosocial behavior and, in the end, increasing social cohesion and synchronization (Decety \& Svetlova, 2012; Hess \& Fischer, 2013) (function). In their study on orangutans (Pongo pygmaeus), Davila-Ross and colleagues (2008) found that nine out of 25 subjects did not show rapid facial mimicry after perceiving play faces in conspecifics. The authors suggested that mimicry in orangutans might be overlaid by socioemotional factors.

It appears clear, then, that mimicry and emotional engagement are phenomena that potentiate each other, thus constituting a positive feedback loop that, in an evolutionary perspective, is extremely adaptive. The evolutionary importance of this loop is underlined by its presence early in life, during the neonatal period, both in human (Jones, 2009) and non-human mammals (Ferrari et al., 2006; MyowaYamakoshi et al., 2004) (ontogeny).

\section{First steps matter: Ontogeny of mimicry}

Tracking signs of imitative mechanism early in life is important to understand its development and the biological features eliciting it (Ferrari et al., 2006; Ray \& Heyes, 2011; Stern, 1985). The earliest form of imitation occurs in newborn's face-to-face interactions with caregivers (Bos et al., 2016; Trevarthen \& Aitken, 2001). Since birth, infants can accurately match facial expressions of others (tongue protrusion, open mouth, and lip protrusion; Meltzoff \& Moore, 1977). Several hypotheses have been put forward to identify which mechanisms might underlie neonatal imitation (Jones, 2009; Meltzoff \& Decety, 2003). One of them claims that, in humans, this phenomenon is probably accomplished through active inter-modal matching (AIM), mediated by an innate representational system (Meltzoff \& Moore, 1977, 1983, 1989). The AIM model is an active inter-modal matching based on "the neonate's capacity to represent visually and proprioceptively perceived information in a form common to both modalities." (Meltzoff \& Moore, 1977, p. 78).

The presence of neonatal imitation in human and nonhuman primate infants (chimpanzees, Myowa-Yamakoshi et al., 2004; rhesus macaques, Ferrari et al., 2006) supports the AIM hypothesis, which is also held by neurophysiology. The neurophysiological approach proposes that the phenomenon relies on a non-completely developed mirror mechanism already present at birth (Casile et al., 2011). Another possible explanation for the presence of neonatal imitation suggests that the mimic capacity of newborns is mediated by an "innate releasing mechanism" based on simple reflexes such as the Moro reflex (Gottlieb, 2007; Thelen \& Smith, 1994).

Whatever the hypothesis considered, laboratory data indicate that the ability to mirror the behavior of others, although present at birth (Anisfeld et al., 2001), disappears at approximately 2-3 months of age in humans and chimpanzees (Jacobson, 1979; Myowa-Yamakoshi et al., 2004) and in the second week of life in monkeys (Ferrari et al., 2006). The fact that this period lasts longer in humans and great apes with respect to monkeys may be relevant to species differences in adult social cognition, although this hypothesis has to be explored and quantitatively demonstrated. A recent work by Kaburu et al. (2016) demonstrated that the infant macaque's ability (Macaca mulatta) to imitate a caregiver's oral movements (lip smacking) predicts the development of infant temperament. Compared to the non-imitators, the imitator newborns showed a greater social competence, lower anxiety 
levels, and higher levels of play behavior at 1 year of age. These findings suggest that neonatal imitation not only has a role in the development of infants' social skills in the first weeks of life, but that it has repercussions on the longer developmental trajectories encompassing the first year of life.

The lack of neonatal imitation processes recorded at a later stage could be due to biases introduced by the experimental approach in the lab. Artificial rearing conditions, the unnatural source of stimuli (experimenter's face; non-biological stimulus) and the facial expressions used as a stimulus which are not yet present in the facial repertoire of the newborn can have a strong impact on the facial response of the infant. All the studies we cited did not focus on rapid facial mimicry, but they took into account other forms of imitation requiring longer times of reaction.

The first step in ascertaining the earliest presence of any kind of imitative process, including rapid facial mimicry, is the assessment of the ontogeny of the facial expression repertoire in a given species. This approach is crucial to select the appropriate stimulus to be proposed in a specific stage of life.

Recently, Isomura and Nakano (2016) explored facial mimicry in 5-month-old infants by measuring facial electromyographic activity (EMG) during the observation of audiovisual stimuli (bimodal signal). As opposed to other studies that made use of a unimodal triggering stimulus, the authors found clear evidence of bimodal mimicry in the tested infants. This study underlines the importance to select the appropriate modality (unimodality vs. multimodality) of the stimulus to have reliable data on the rapid mimicry phenomenon.

Another crucial point is about the development of the repertoire of facial expressions. The stimulation of an infant with a facial expression that he/she will develop only later in life cannot give any insights in understanding the development of mimicry phenomenon. The application of a naturalistic approach to investigate rapid mimicry in infants automatically rules out all the biases typical of the lab studies. The natural stimulus produced by the mother or conspecifics, the social context under which the facial expression is performed (Bos et al., 2016), and the lack of any forms of physical limitation of the infant, who is free to move and watch around, make this approach extremely valuable not only to investigate the possible presence of the phenomenon but also its immediate function and role during social interactions (function).

Geladas (Theropithecus gelada) are a species on which our research group has been focusing attention since 2007. Over 10 years, we collected longitudinal data on a stable captive colony, thus being able to follow the growth of several subjects since their birth (Mancini et al., 2013a,b; Palagi et al., 2009; Palagi \& Mancini, 2011). An analysis of the ontogenetic emergence of facial expressions revealed that the earliest facial display clearly discernible was the Open Mouth (the mouth is opened in a relaxed mood shaped like an oval). During the first week of life the newborn shows this pattern while interacting both with the mother and other subjects. In this species, due to its tolerant nature (Pallante et al., 2016), social canalization is limited and the permissiveness of the mothers allows other subjects to interact directly with the newborn (Berman, 1982). For this reason it is also common to observe gentle playful stimulation from other group members towards infants during their first days of life (Palagi et al., unpublished data). In the fifth week when play becomes a true exchange of behavioral patterns between the playmates, infants' Play Face emerges (the mouth is widely opened in a relaxed mood with lower teeth/gums always exposed and upper teeth/gums occasionally exposed; van Hooff, 1972, 1989) and concurrently Open Mouth frequency decreases (Fig. 1). This inverse relationship suggests that the Open Mouth display could represent a form of precursor of the more contextualized form of facial expression typical of play, the Play Face. It is worth noting that in geladas, rapid facial mimicry does not occur before the second month of life, in concurrence with the emergence of the Play Face. During the first month of life, when the only facial expression performed is the Open Mouth, we did not record any correspondence between the stimulus perceived and the response emitted. The specificity of the rapid facial mimicry phenomenon for the Play Face as a stimulus also persists later in life. Mancini and coworkers (2013a) found that both immature and adult subjects mimicked Play Faces but not Lip Smacking (the lips are protruded and then smacked together repeatedly). As opposed to Play Face, Lip Smacking is a signal that can embrace different functions depending on the species, on the context in which it is performed, and on the target subject to which it is directed (Maestripieri, 1997; Palagi \& Mancini, 2011). Play Faces are unambiguous signals conveying a message of a positive emotion arising from play, a well-known self-rewarding behavior (Burghardt, 2005; van Hooff \& Preuschoft, 2003). Through rapid facial mimicry, play faces elicit in the perceiver the same positive emotional state. The ability to immediately mirror the facial expression and generate the same emotion is adaptive, as it allows an individual to foresee playmates' intentions and fine-tune its own motor sequences accordingly (Palagi et al., 2016a) (function).

\section{From the development to the function: How mimicry creates emotional bridges}

It is evident that the phenomenon of mimicry, which plays an important social role during adulthood, is deeply rooted in the first days after birth. The extremely sensitive and mouldable developmental/maturation period and, in particular, the appropriateness of the stimuli perceived by the newborn seems to be fundamental for the subject to reach his or her full ability to emotionally synchronize with others (ontogeny). Even though it is not a conditio sine qua non, the appropriate stimuli proposed during the developmental 


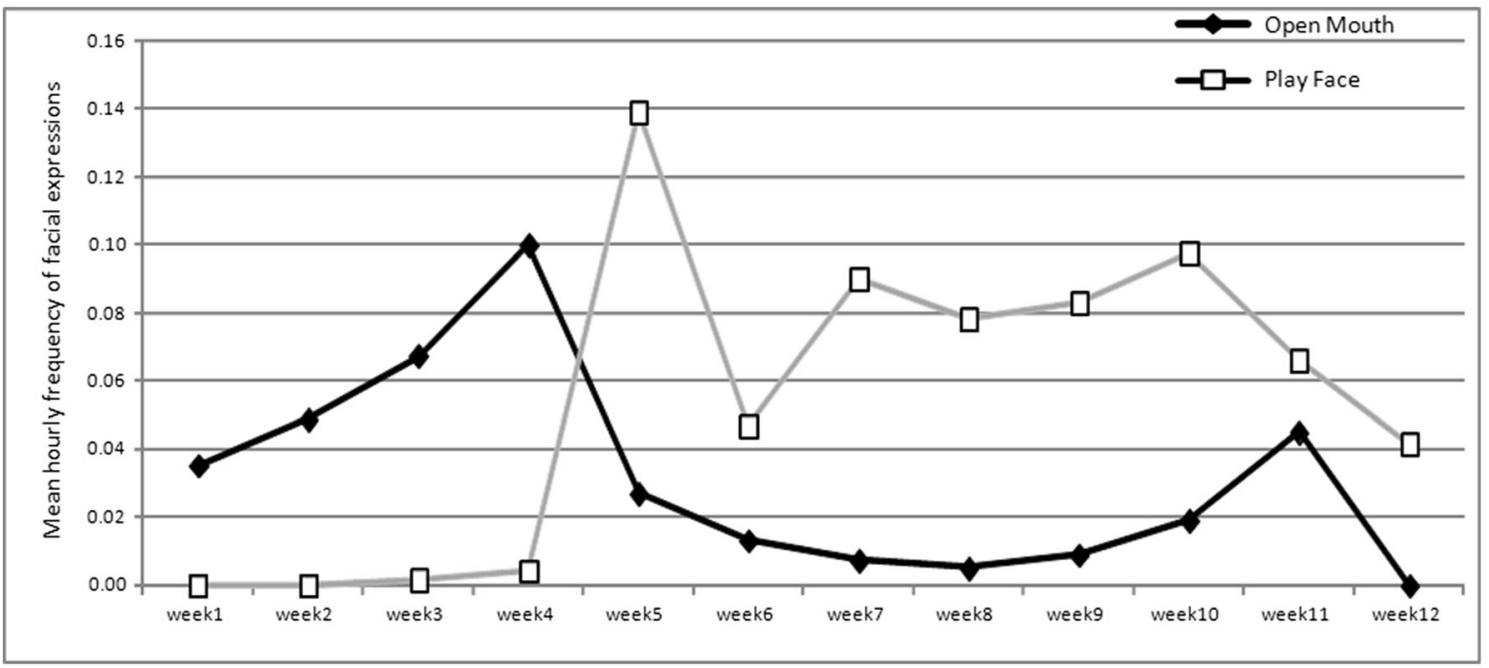

Fig. 1 Mean hourly frequency of Open Mouth (black line and square) and Play Face (gray line and white square) as a function of a week of life in Theropithecus gelada infants

stage are a good prerequisite to later avoid any misunderstanding, manage interactions successfully, promote social affiliation, and, as a consequence, to become aware of contingencies in the social world (Ferrari et al., 2006). For all these reasons, behavioral mimicry has therefore been referred to as "social glue" (Lakin et al., 2003). In complex societies, being able to coordinate for common purposes, perceiving others' affective state and signaling one's own, are all skills deeply linked to the communicative repertoire of gestures and facial expressions typical of a given species (Palagi et al., 2016a). Hence, before exploring the phenomenon of mimicry, each specific facial expression/body posture and the context in which it occurs should be analyzed.

Play is a valuable context in which humans and other social mammals can test themselves by cooperating and challenging others in a relatively safe way (Fagen, 1981). During play different facial expressions can be present, although only Play Face (or Relaxed Open Mouth, or Laugh) is context specific and seems to be homologous/analogous across many species of mammals (Palagi et al., 2016a).

Play faces are important to reach and maintain the behavioral agreement that is necessary to prolong a playful interaction (Waller \& Dunbar, 2005). In bonobos, play faces are frequent when the risk of misleading is particularly high. In this species, polyadic play sessions, the most unpredictable play sessions, were punctuated by a higher number of playful facial displays. Among adult bonobo females, play fighting can have a competitive nature, which serves to test a partner's willingness to invest in a relationship and simultaneously to show willingness to accept vulnerability (Palagi, 2006). Since adult play fighting implies a certain amount of roughness, a clear declaration of intent and/or good synchronization are needed. In bonobos, when play involves adults that are similar in age and size, the sessions are particularly rich in facial expressions. This suggests that an intentional component, in addition to an emotional component, can drive the performance of a facial expression in this species (Demuru et al., 2015).

There are many reports in the literature revealing that the mere presence of playful facial expressions prolongs the playful interactions, thus making play more successful and rewarding (see Palagi et al., 2016a for an extensive review). However, recently some researchers suggested that the reciprocity of the signal (delayed response, $5 \mathrm{~s}$ ) and the phenomenon of rapid mimicry (fast response occurring within $1 \mathrm{~s}$ after the perception of the stimulus) are probably the driving force that motivates the players to prolong their playful interaction. In South American sea lions, the use of Relaxed Open Mouth was frequently reciprocated between players sharing good relationships, especially when they had the highest probability of engaging in a face-to-face interaction (e.g., dyadic play). Reciprocation was measured as the number of relaxed open mouth events exchanged by the players in a single playful session independent from the time latency separating the two events. Moreover, the authors found that the reciprocity of the Relaxed Open Mouth display, more than its mere frequency, was effective in prolonging the playful session (Llamazares-Martín et al., 2017). Therefore, the attentional selectiveness of the receiver, unveiled by his or her facial congruent reaction, seems to be fundamental for the facial signal to efficiently convey the message "I am still motivated to play, and you?" Critically, this reciprocity of play signals is less sophisticated than the rapid mimicry characterizing other mammal species but, at the same time, it shows how a simpler version of emotional exchanging can be important for facilitating play. These findings should stimulate further research to examine playful signals in other species to determine if signal reciprocity is a feature of play generally or whether it is present only in species with more competitive forms of play fighting, as is the case with South American sea lions. The findings 
raise important theoretical issues. For example, is this simpler form of signaling reciprocity a necessary precursor for evolving rapid mimicry (evolution)? The presence of rapid mimicry seems to be even more effective in prolonging the playful session compared to simple reciprocation. Mancini and coworkers (2013b) found that in geladas the timing of reaction matters. Rapid facial mimicry appears to convey more important information to the playmate; in fact, it signals not only that the stimulus has been perceived but that it has been accurately interpreted. Rapid mimicry limits the possible ambiguity generated by a lack of response or by an incongruent reaction that may reveal a non-clear interpretation of the signal by the receiver. Thus, facial mimicry, by facilitating communicative exchanges and behavioral coordination in the sequence of players' actions, significantly prolongs the session itself. Experiencing high motivation to play and playing for longer is advantageous for the playmates who increase the opportunity to assess their reciprocal ability and to test their social relationship (Mancini et al., 2013b). The highest levels of rapid facial mimicry in geladas were found between mothers and their offspring, at least during the first months of life, although infants already exchange playful interactions with peers and unrelated adults (Mancini et al., 2013a). The peculiarity of mother-offspring facial mimicry resided not only in their high frequency of response but also in the time latency in which they responded each other. Compared to other dyads, the mirror responses between mothers and their infants were the fastest (Mancini et al., 2013a). The face-to-face engagement occurring between mothers and infants has been extensively explored and documented in humans (Feldman, 2007, 2010). Affective matching, mediated by motor resonance, is important for neuro-physiological maturation and for the attachment relationship of the infant with the caregiver. In nonhuman primates, rapid mimicry could reflect one of the core elements of the mother-infant relationship (the attachment) and might represent one of the first steps (ontogeny) in the formation of the emotional bridge between the infant and the social environment.

Fawcett and Liszkowski (2012) found that spontaneous imitation in play is predictive of infants' motivation to engage in future play sessions with familiar adults. Eighteen-monthold infants initiated play interactions more frequently both when they were the triggers and when they were the receivers of the imitative event. These findings suggest that both being imitated and imitating others can represent a non-verbal instrument in conveying motivation to invest in future interactions and to develop social bridges between play partners.

Domestic dogs provide interesting evidence about the importance of mimicry phenomena to communicate with others (Palagi et al., 2015). To signal their motivation to play, both with humans and conspecifics, dogs can combine different body postures (e.g., head, tail) and the expressive use of the eyes and mouth (Horowitz, 2009). Moreover, such multi- component communication also seems to play an important role in conveying emotional states (Quaranta et al., 2007). As emotions are unveiled by the subject through motor action patterns (Anderson \& Adolphs, 2014), it is adaptive for the receiver to be able to perceive and decode others' behavioral displays, thus appropriately interpreting the emotional states underpinning such displays. Dogs are able to discriminate not only the displays performed by other dogs, but also those performed by humans, such as facial expressions (Müller et al., 2015) and body postures (Rooney et al., 2001).

In dogs two signals are specific for play, the Relaxed Open Mouth and the Play Bow (for a definition see Bekoff \& Allen, 1998; Palagi et al., 2016a; Smuts, 2014). Both signals can be concurrently present during both dog-human and dog-dog interactions. In 2015, Palagi and coworkers demonstrated the presence of rapid mimicry in dogs. By studying intra-species playful sessions, the authors focused not only on facial mimicry but also on body mimicry. Dogs responded in a congruent and extremely rapid way $(<1 \mathrm{~s})$ both when the trigger stimulus was a relaxed open mouth (rapid facial mimicry) and when the stimulus was a play bow (rapid body mimicry). This indicates that mimicry is not limited to facial signals but that a more generalized behavioral mimicry can be developed as a function of the species, the context, the behavioral repertoire, and the emotional linkage present between the two interacting subjects (Duffy \& Chartrand, 2015). Even though we cannot separate the cause-effect relationship between facial and body mimicry and the emotional engagement and motivation to play, it seems that in dogs the phenomena are tied and that a positive affective state can be shared between players. This emotional sharing can be at the basis of the success of those play sessions characterized by the presence of mimicry. When both facial and body mimicry events occurred, the two players engaged in longer playful sessions (Palagi et al., 2015).

In human and non-human primates an "empathic gradient" exists as a function of the level of familiarity between the interacting subjects. Yawn contagion (Norscia \& Palagi, 2011) and facial mimicry (Duffy \& Chartrand, 2015; Hess \& Fischer, 2013; Mancini et al., 2013b) were strongly affected by the intimacy shared by the subjects involved: the higher the intimacy between subjects, the higher the level of their mimicry. The effect of familiarity also positively regulates mimicry in the domestic dog. By experiencing a higher level of emotional identification, dogs that are socially close engaged in high levels of facial and body mimicry (Palagi et al., 2015). Exploring rapid mimicry in wolves could help evaluate whether the phenomenon in dogs is linked to the domestication process or if it is evolutionarily rooted in social carnivores (evolution).

In conclusion, facial and body mimicry is not merely the association between a sensory input (perception) and a motor output (behavior), but rather a phenomenon that is unconsciously activated and modulated by social and emotional 
affiliation (Chartrand et al., 2005; Duffy \& Chartrand, 2015) (proximate causation). Mimicry fosters emotional engagement (longer play duration), emotional engagement increases social closeness and synchronization (familiarity), social closeness increases the probability for mimicry to occur (function). This self-sustained loop is probably at the basis of the affective bridges in human and non-human animals.

\section{The evolutionary pathways of mimicry reflect the nature of social networks}

One of the core aspects of play is the ability to imitate peers: the performance of same acts is the predominant mode of social interactions among toddlers and non-human infants in general. These imitative exchanges promote social interactions by communicating a common understanding of ongoing activities (function) and are fundamental for the development of more advanced play skills at later ages (Kaburu et al., 2016; Morrison \& Kuhn, 1983) (ontogeny). The possibility for infants to interact with other group members, both peers and adults, is therefore crucial (Fawcett \& Liszkowski, 2012). A key role is played by the nature of the mother-offspring interaction, which determines the social space of the infant. The different maternal styles imply different levels of restrictiveness towards infants who become more or less able to develop social competence and to increase their social networks. Infants who are highly socially canalized are generally less able to cope with social challenges and unpredictable situations. In human and non-human primates, the evolution of maternal styles can be viewed as an adaptation to evolutionary changes in adult social relationships and organization (Butovskaya, 2004). In hunter-gatherer societies characterized by high levels of social tolerance and cooperation in social relationships, social canalization is reduced and parents leave their children free to play with all the members of the community independent of their age and sex. Play is considered as a tool for child education (for an extensive review see Gray, 2009; Pellegrini, 2009, 2011; Power, 2000). In non-human primates, there is important evidence demonstrating that a covariation exists between despotic/nepotistic social relationships and the high level of maternal restrictiveness and, therefore, strong infant social canalization (Berman \& Kapsalis, 1999; Chauvin \& Berman, 2004; Thierry, 2004). Mothers living in highly despotic societies tend to protect their infants and canalize their socialization almost exclusively towards kin. This limits the possibility of infants to manage unexpected situations, enlarge their social networks, and assess their own social and physical abilities with a larger sphere of individuals. The narrow knowledge of psychological, social, and physical skills of others will produce highly crystallized adult roles (ontogeny). The pervasiveness and incidence of play within a society are predictive of the tolerant nature of that society (Palagi et al., 2016b; Petit et al., 2008).
Mimicry improves communicative exchanges between the playmates and, at the same time, promotes behavioral coordination and synchronization (Palagi et al., 2016a,b). This motor resonance phenomenon reaches its functional and beneficial climax when play is characterized by the maximum degree of freedom in the sequence of actions and by a strong variability in the sex, age, and number of players involved (Ciani et al., 2012).

Tolerant species are well known to engage in social play at every age and independent of the sex of the participants (Mancini \& Palagi, 2009; Palagi, 2006, 2008). For this reason, individuals living in tolerant societies are expected to make stronger use of mimicry to cope with playful unpredictability. To verify this hypothesis, Scopa and Palagi (2016) investigated the repertoire of facial expressions and rapid mimicry in two species of macaques characterized by strikingly different social styles (Thierry, 1985, 2007): Macaca tonkeana, one of the most tolerant species, and Macaca fuscata, one of the most despotic species (Thierry, 2000). Contrary to Japanese macaques, Tonkean macaques frequently reconcile their conflicts (Demaria \& Thierry, 2001) and engage in affiliative contacts independently from the level of kinship and hierarchical status of the subjects (Adams et al., 2015).

In play, Japanese macaques are competitive with little physical contact and low-risk strategies (Petit et al., 2008; Reinhart et al., 2010). In this species, the inhibition of motor acts and physical contacts characterizing play seems to reflect the crystallized roles of individuals, which are arranged according to rank and kinship rules. On the contrary, playful interactions in Tonkean macaques are less defensive, more cooperative (Reinhart et al., 2010), and less age- and genderbiased (Ciani et al., 2012). Moreover, in Tonkean macaques a strong redundancy and complexity of facial expressions have evolved in the play domain (Preuschoft, 2004; Micheletta et al., 2013). Play signal pervasiveness and variability are excellent prerequisites for facial mimicry to occur. As expected, Scopa and Palagi (2016) failed to find rapid facial mimicry in Japanese macaques, whereas, the phenomenon was observed in Tonkean macaques. In this species, rapid facial mimicry occurred only when a play face was the triggering stimulus with other facial expressions (e.g., lip smacking), also occurring in play, not eliciting the congruent response. A similar result was found for Theropithecus gelada (Mancini et al., 2013a). Lip smacking is a signal that has different meanings according to (i) the context in which it occurs, (ii) the receiver to which it is directed, and (iii) the species (Palagi \& Mancini, 2011). Therefore, the absence of rapid facial mimicry in response to lip smacking could be due to its non-context-specific nature. Probably, additional data collected outside the playful context could illuminate this issue. Contrary to lip smacking, play faces unveil an unambiguous positive emotion arising from play, an emotionally positive and self-rewarding behavior, especially in those tolerant 
species in which play performance is detached from any hierarchical and kin rules. In these species, the emotional component of the triggering signal could be the driving force at the basis of the rapid congruent response emitted by the receiver.

The strong similarity of the neurological structure organization of Macaca tonkeana and Macaca fuscata (Delson, 1980; Gibson, 1977) rules out the possibility that Japanese macaques do not have the neural potential to be infected by others' facial expressions (proximate causation). Therefore, the absence of rapid facial mimicry in Macaca fuscata can be ascribed to the limitation of social play and affiliation that do not provide the affective basis essential for emotional contagion to be expressed. For this reason, the opposite social styles characterizing the two macaque species (Thierry, 2000) and the limited playful facial expression repertoire of Macaca fuscata can concur in affecting the different level of susceptibility to others' play faces. An investigation on rapid facial mimicry in those macaque species showing an intermediate level of despotism (e.g., Macaca sylvanus, Macaca fascicularis) could provide insights on the level of social modulation affecting this phenomenon.

Davila-Ross and coworkers (2011) found that in chimpanzees both rapid (automatic response occurring within $1 \mathrm{~s}$ after the perception of the stimulus) and delayed facial mimicry (less automatic response occurring between 1 and $5 \mathrm{~s}$ after the perception of the stimulus) are present.

Rapid and delayed facial mimicry events are not part of the same continuum, but they are qualitatively different, reflecting a partial differential modulation from the underlying neural substrates (Gervais \& Wilson, 2005). Compared to rapid mimicry, delayed mimicry has been proposed to be a nonautomatic response that is probably under voluntary control and likely detached from emotions (Mancini et al., 2013a). Focusing on lowland gorillas (Gorilla gorilla gorilla), Palagi and colleagues (unpublished data) observed rapid but not delayed facial mimicry in this species. Moreover, gorillas showed a perfect facial matching response (Play Face $\rightarrow$ Play Face; Full Play Face $\rightarrow$ Full Play Face), which could have an effect on players' behavioral coordination, thus facing the competitive elements characterizing gorilla play fighting (Palagi et al., 2007) (function). Gorillas are organized in harems in which the extremely slack interindividual relationships are limited to a loose spatial proximity. This makes lowland gorillas one of the primate species with the lowest levels of affinitive interactions such as grooming, reconciliation, and support (Harcourt \& Stewart, 1987). Play behavior is a feature of ontogeny that is widely believed to have an important role in the assembly of adult behavior (Burghardt, 2005). Gorilla adult males have to compete to gather reproductive advantages; in this situation, juvenile play fighting may have a strong adaptive role (Nunes et al., 2004). In fact, in this species play fighting is particularly expressed by juvenile males who need to assess their own fighting skills with the best training partners and through the most convenient roughness. The specific and rapid facial matching found in gorillas seems to be mandatory to maintain a playful mood in a species characterized by an extremely low level of social affiliation but that needs play to efficiently shape adult behavior. In this case, contrary to what occurs in the Macaca genus, the strong competition typical of gorilla males could have been the evolutionary engine that led to a more accurate and fast emotional sharing and facial mimicry during play fighting.

The propensity to exchange and reciprocate playful interactions can be predictive of the polarity of changes in tolerance and affiliation between different groups separated either biologically (taxa) or culturally (ethnies). Due to the difficulty in collecting data, information on the possible relation between facial mimicry and different human cultures is scarce. The few data coming from psychological and anthropological literature tend to refer to rapid vocal mimicry (or co-laughter) more than to rapid facial mimicry even though the two phenomena often go in tandem. In some hunter-gatherer societies (!Kung, Africa Kalahari Desert; Hazda, Tanzania rain forest; Mbuti, Congo Ituri Forest; Aka, Central African Republic and Congo rain forests; Efé, Congo Ituri Forest; Batek, Peninsular Malaysia; Agta, Luzon Philippines; Nayaka, South India; Aché, Eastern Paraguay; Parakana, Brazil's Amazon basin; Yiwara, Australia's desert) the flexibility of social relationships and the level of tolerance characterizing them make playful exchange a good tool to manage some adult social practices. Sustenance activities, religious beliefs, sharing food and other-oriented acts, and even punishing cheaters within groups are all activities that can be regulated by humor and ridicule of others (Gray, 2009, 2012). One of the tactics used to solve serious social problems and reduce the level of aggression in group members is co-laughter. Laughing together represents a sort of good-natured teasing that is used to correct or punish those who are in some way disrupting the peaceful mood or violating the rules of the social group. These societies, characterized by highly egalitarian and intensely cooperative social organization, bring all the social aspects of life into the domain of play, thus making the use of physical punishment useless (Gray, 2009). Indeed, in humans, laughing together is a clear signal of cooperative mood (Mehu et al., 2007; Provine, 2013) and "establishes a feeling of closeness and shared identity" (Gray, 2009, p. 490). Psychologists argue that colaughter can be considered as a sort of vocal-grooming that may have evolved to be used as an ice-breaker in those formal situations regulated by more conventional bonding mechanisms (Dezecache \& Dunbar, 2012; Provine, 2013).

One of the issues to be clarified is whether co-laughter is a culturally (or intentionally) or a biologically (or emotionally) driven phenomenon that can be shaped by natural selection. Recent findings showed that the potential use of co-laughter in 
different human societies can be explained not only by cultural but also by biological factors (Bryant et al., 2016). The authors experimentally demonstrated that listeners speaking different languages and belonging to 24 different societies distributed all over the world (see http://www.pnas.org/ content/suppl/2016/04/05/1524993113.DCSupplemental for details) were able to reliably distinguish between friends and strangers by only hearing a short audio-record of co-laughing of American English speakers. This study indicates that vocal mimicry (or co-laughter) is perceivable and detectable across the world as a valuable communicative signal of relationship quality. Even though the evolution of symbolic language has opened new pathways for evolutionarily unparalleled levels of cooperative complexity in humans, we are still making use of unconscious facial/vocal signals of affiliation that apparently have anticipated more derived forms of communication. From an evolutionary point of view, in the ancestral past of our species, individuals who could accurately decipher the nonverbal communicative exchange between others thereby interpreting their degree of affiliation, probably stood to gain higher rewards in terms of fitness benefits. In conclusion, human vocal mimicry might have been the driving force facilitating the evolution of social bonding and cooperation in Homo sapiens.

\section{Conclusion}

Rapid mimicry is an unconscious and automatic form of emotional sharing that can be modulated by socio-ecological and cultural factors. One of the main challenging concerns is to explore the mimicry phenomenon by integrating the different approaches, including the ethological one, in a multidisciplinary way. This review has tried to fill the gap. However, many pieces of information are still lacking in order to build a deeper framework of this sophisticated and complex form of communication. Data on rapid mimicry mainly derive from lab research, which, although it has been providing many suggestions on the proximate causes, does not provide information about contextual and socio-ecological correlates. Only by integrating laboratory and naturalistic-observational approaches will we be able to really understand one of the most important communicative traits that have probably developed and shaped our innate tendency to sociality.

Acknowledgements We wish to thank Lance Miller and Alex de Voogt for organizing the Leading Edge Workshop entitled "The Evolutionary and Psychological Significance of Play" and Lou Shomette and the Play Psychonomic Society for supporting and sponsoring this event. We wish to thank W. Pecorino for his important clarifying input in discussing results. This contribution is dedicated to the memory of Stanley A. Kuczaj, who studied play through Tinbergen's lens.

\section{References}

Adams, M. J., Majolo, B., Ostner, J., Schülke, O., De Marco, A., Thierry, B., . . . Weiss, A. (2015). Personality structure and social style in macaques. Journal of Personality and Social Psychology, 109, 338353. doi:10.1037/pspp0000041

Anderson, D. J., \& Adolphs, R. (2014). A framework for studying emotions across species. Cell, 157, 187-200. doi:10.1016/j.cell.2014.03.003

Anisfeld, M., Turkewitz, G., Rose, S. A., Rosenberg, F. R., Sheiber, F. J., Couturier-Fagan, D. A., . . . Sommer, I. (2001). No compelling evidence that newborns imitate oral gestures. Infancy, 2, 111-122.

Bekoff, M., \& Allen, C. (1998). Intentional communication and social play: how and why animals negotiate and agree to play. Animal play: Evolutionary, comparative, and ecological perspectives, 97114.

Berman, C. M. (1982). The ontogeny of social relationships with group companions among free-ranging infant rhesus monkeys II. Differentiation and attractiveness. Animal Behaviour, 30, 163-170. doi:10.1016/S0003-3472(82)80251-0

Berman, C. M., \& Kapsalis, E. (1999). Development of kin bias among rhesus monkeys: Maternal transmission or individual learning? Animal Behaviour, 58, 883-894. doi:10.1006/anbe.1999.1221

Bos, P. A., Jap-Tjong, N., Spencer, H., \& Hofman, D. (2016). Social context modulates facial imitation of children's emotional expressions. PloS ONE, 11, article number: e0167991. doi:10.1371/ journal.pone. 0167991

Bourgeois, P., \& Hess, U. (2008). The impact of social context on mimicry. Biological Psychology, 77, 343-352. doi:10.1016/j.biopsycho. 2007.11.008

Bryant, G. A., Fessler, D. M. T., Fusaroli, R., Clint, E., Aarøef, L., ... .Zhoup, Y. (2016). Detecting affiliation in colaughter across 24 societies. Proceedings of the National Academy of Sciences, 113, 4682-4687. doi: 10.1073/pnas.1524993113

Burghardt, G. M. (2005). The genesis of animal play: Testing the limits. Cambridge: MIT Press.

Butovskaya, M. (2004). Social space and degrees of freedom. In B. Thierry, M. Singh, \& W. Kaumanns (Eds.), Macaque societies: A model for the study of social organization (pp. 182-185). Cambridge: Cambridge University Press.

Byrne, R. W. (1994). The evolution of intelligence. In P. J. B. Slater \& T. R. Halliday (Eds.), Behavior and evolution (pp. 223-264). Cambridge: Cambridge University Press.

Call, J., \& Tomasello, M. (1995). Use of social information in the problem solving of orangutans (Pongo pygmaeus) and human children (Homo sapiens). Journal of Comparative Psychology, 109, 308320. doi:10.1037/0735-7036.109.3.308

Casile, A., Caggiano, V., \& Ferrari, P. F. (2011). The mirror neuron system: a fresh view. The Neuroscientist, 17, 5. doi:10.1177/ 1073858410392239

Chartrand, T. L., Maddux, W. W., \& Lakin, J. L. (2005). Beyond the perception-behavior link: The ubiquitous utility and motivational moderators of nonconscious mimicry. The New Unconscious, 334-361.

Chauvin, C., \& Berman, C. M. (2004). 10 Intergenerational transmission of behavior. In B. Thierry, M. Singh, \& W. Kaumanns (Eds.), Macaque societies: A model for the study of social organization (pp. 209-230). Cambridge: Cambridge University Press.

Ciani, F., Dall'Olio, S., Stanyon, R., \& Palagi, E. (2012). Social tolerance and adult play in macaque societies: A comparison with different human cultures. Animal Behaviour, 84, 1313-1322. doi:10.1016/j. anbehav.2012.09.002

Davila-Ross, M., Menzler, S., \& Zimmermann, E. (2008). Rapid facial mimicry in orangutan play. Biology Letters, 4, 27-30. doi:10.1098/ rsbl.2007.0535 
Davila-Ross, M., Allcock, B., Thomas, C., \& Bard, K. A. (2011). Aping expressions? Chimpanzees produce distinct laugh types when responding to laughter of others. Emotion, 11, 1013. doi:10.1037/ a0022594

Decety, J., \& Svetlova, M. (2012). Putting together phylogenetic and ontogenetic perspectives on empathy. Developmental Cognitive Neuroscience, 2, 1-24. doi:10.1016/j.den.2011.05.003

Delson, E. (1980). Fossil macaques, phyletic relationships and a scenario of deployment. The Macaques: Studies in ecology, behavior and evolution, 10-30.

Demaria, C., \& Thierry, B. (2001). A comparative study of reconciliation in rhesus and Tonkean macaques. Behaviour, 138, 397-410. doi:10. 1163/15685390152032514

Demuru, E., Ferrari, P. F., \& Palagi, E. (2015). Emotionality and intentionality in bonobo playful communication. Animal Cognition, 18, 333-344. doi:10.1007/s10071-014-0804-6

Dezecache, G., \& Dunbar, R. I. M. (2012). Sharing the joke: The size of natural laughter groups. Evolution and Human Behavior, 33, 775779. doi:10.1016/j.tics.2012.11.001

Dezecache, G., Jacob, P., \& Grèzes, J. (2015). Emotional contagion: Its scope and limits. Trends in Cognitive Sciences, 19, 297-299. doi:10. 1016/j.tics.2015.03.011

Dimberg, U., \& Thunberg, M. (1998). Rapid facial reactions to emotional facial expressions. Scandinavian Journal of Psychology, 39, 39-45. doi:10.1111/1467-9450.00054

di Pellegrino, G., Fadiga, L., Fogassi, L., Gallese, V., \& Rizzolatti, G. (1992). Understanding motor events: A neurophysiological study. Experimental Brain Research, 91, 176-180. doi:10.1007/ BF00230027

Duffy, K. A., \& Chartrand, T. L. (2015). Mimicry: causes and consequences. Current Opinion in Behavioral Sciences, 3, 112-116. doi:10.1016/j.cobeha.2015.03.002

Fagen, R. A. (1981). Animal play behavior. Oxford: Oxford University Press.

Fawcett, C., \& Liszkowski, U. (2012). Mimicry and play initiation in 18month-old infants. Infant Behavior and Development, 35, 689-696. doi:10.1016/j.infbeh.2012.07.014

Feldman, R. (2007). Parent-infant synchrony and the construction of shared timing; physiological precursors, developmental outcomes, and risk conditions. Journal of Child Psychology and Psychiatry, 49, 329-354. doi:10.1111/j.1469-7610.2006.01701.x

Feldman, R. (2010). The relational basis of adolescent adjustment: Trajectories of mother child interactive behaviors from infancy to adolescence shape adolescents' adaptation. Attachment and Human Development, 12, 173-92. doi:10.1080/14616730903282472

Ferrari, P. F., Visalberghi, E., Paukner, A., Fogassi, L., Ruggiero, A., \& Suomi, S. J. (2006). Neonatal imitation in rhesus macaques. PLoS Biology, 4, article number: e302. doi:10.1371/journal.pbio.0040302

Ferrari, P. F., Bonini, L., \& Fogassi, L. (2009). From monkey mirror neurons to primate behaviours: Possible 'direct'and 'indirect'pathways. Philosophical Transactions of the Royal Society of London B: Biological Sciences, 364, 2311-2323. doi: 10.1098/rstb.2009.0062

Flack, W. (2006). Peripheral feedback effects of facial expressions, bodily postures, and vocal expressions on emotional feelings. Cognition \& Emotion, 20, 177-195. doi:10.1080/02699930500359617

Gallese, V., Fadiga, L., Fogassi, L., \& Rizzolatti, G. (1996). Action recognition in the premotor cortex. Brain, 119, 593-609. doi:10.1093/ brain/119.2.593

Gallese, V., Keysers, C., \& Rizzolatti, G. (2004). A unifying view of the basis of social cognition. Trends in Cognitive Sciences, 8, 396-403. doi:10.1016/j.tics.2004.07.002

Gervais, M., \& Wilson, D. S. (2005). The evolutions and functions of laughter and humor: A synthetic approach. The Quarterly Review of Biology, 80, 395-430. doi:10.1086/498281
Gibson, K. R. (1977). Brain structure and intelligence in macaques and human infants from a Piagetian perspective. Primate biosocial development: Biological, social, and ecological determinants, 113157.

Gottlieb, G. (2007). Probabilistic epigenesis. Developmental Science, 10, 1-11. doi:10.1111/j.1467-7687.2007.00556.x

Gray, P. (2009). Play as a foundation for hunter-gatherer social existence. American Journal of Play, 1, 476-522.

Gray, P. (2012). The value of a play-filled childhood in development of the hunter-gatherer individual. In D. Narvaez, J. Panksepp, A. Shore, \& T. Gleason (Eds.), Human nature, early experience and the environment of evolutionary adaptedness. New York: Oxford University Press.

Harcourt, A. H., \& Stewart, K. J. (1987). The influence of help in contests on dominance rank in primates: Hints from gorillas. Animal Behaviour, 35, 182-190. doi:10.1016/S0003-3472(87)80223-3

Hatfield, E., Cacioppo, J. T., \& Rapson, R. L. (1994). Emotional contagion: Cambridge studies in emotion and social interaction. Cambridge, UK: Cambridge University Press. Errors-in-Variables Regression Model When the Variances of the Measurement Errors Vary Between the Observations. Statistics in Medicine, 21, 1089-1101.

Hecht, J., Miklósi, Á., \& Gácsi, M. (2012). Behavioral assessment and owner perceptions of behaviors associated with guilt in dogs. Applied Animal Behaviour Science, 139, 134-142. doi:10.1016/j. applanim.2012.02.015

Hess, U., \& Fischer, A. (2013). Emotional mimicry as social regulation. Personality and Social Psychology Review, 17, 142-157. doi:10. 1177/1088868312472607

Hofman, D., Bos, P. A., Schutter, D. J., \& van Honk, J. (2012). Fairness modulates non-conscious facial mimicry in women. Proceedings of the Royal Society B: Biological Sciences, 279, 3535-3539. doi:10. 1098/rspb.2012.0694

Horowitz, A. (2009). Attention to attention in domestic dog (Canis familiaris) dyadic play. Animal Cognition, 12, 107-118. doi:10. 1007/s10071-008-0175-y

Isomura, T., \& Nakano, T. (2016). Automatic facial mimicry in response to dynamic emotional stimuli in five-month-old infants. Proceedings of the Royal Society B: Biological Sciences, 283, 20161948. doi:10.1098/rspb.2016.1948

Jacobson, S. W. (1979). Matching behavior in the young infant. Child Development, 50, 425-430. doi:10.2307/1129418

Jones, S. S. (2009). The development of imitation in infancy. Philosophical Transactions of the Royal Society, B: Biological Sciences, 364, 2325-2335. doi:10.1098/rstb.2009.0045

Kaburu, S. S. K., Paukner, A., Simpson, E. A., Suomi, S. J., \& Ferrari, P. F. (2016). Neonatal imitation predicts infant rhesus macaque (Macaca mulatta) social and anxiety-related behaviours at one year. Scientific Reports 6, article number: 34997. doi:10.1038/srep34997

Lakin, J. L., Jefferis, V. E., Cheng, C. M., \& Chartrand, T. L. (2003). The chameleon effect as social glue: Evidence for the evolutionary significance of nonconscious mimicry. Journal of Nonverbal Behavior, 27. 145-162. doi:10.1023/A:1025389814290

Llamazares-Martín, C., Scopa, C., Guillén-Salazar, F., \& Palagi, E. (2017). Relaxed open mouth reciprocity favours playful contacts in South American sea lions (Otaria flavescens). (published online) https://doi.org/10.1016/j.beproc.2017.04.007

Mancini, G., \& Palagi, E. (2009). Play and social dynamics in a captive herd of gelada baboons (Theropithecus gelada). Behavioural Processes, 82, 286-292. doi:10.1016/j.beproc.2009.07.007

Maestripieri, D. (1997). Gestural communication in macaques: Usage and meaning of nonvocal signals. Evolution of Communication, 1, 193222. doi:10.1075/eoc.1.2.03mae

Mancini, G., Ferrari, P. F., \& Palagi, E. (2013a). Rapid facial mimicry in geladas. Scientific Reports, 3, 1527. doi:10.1038/srep01527

Mancini, G., Ferrari, P.F., \& Palagi, E. (2013b). In play we trust. Rapid facial mimicry predicts the duration of playful interactions in 
geladas. PLoS ONE 8, article number:e66481. doi: 10.1371/journal. pone.0066481

Mehu, M., Grammer, K., \& Dunbar, R. I. (2007). Smiles when sharing. Evolution and Human Behavior, 28, 415-422. doi:10.1016/j. evolhumbehav.2007.05.010

Meltzoff, A. N., \& Moore, M. K. (1977). Imitation of facial and manual gestures by human neonates. Science, 198, 75-78.

Meltzoff, A. N., \& Moore, M. K. (1983). Newborn infants imitate adult facial gestures. Child Development, 702-709. doi:10.2307/1130058

Meltzoff, A. N., \& Moore, M. K. (1989). Imitation in newborn infants: Exploring the range of gestures imitated and the underlying mechanisms. Developmental Psychology, 25, 954. doi:10.1037/00121649.25.6.954

Meltzoff, A. N., \& Decety, J. (2003). What imitation tells us about social cognition: A rapprochement between developmental psychology and cognitive neuroscience. Philosophical Transactions of the Royal Society of London B: Biological Sciences, 358, 491-500. doi:10.1098/rstb.2002.1261

Micheletta, J., Engelhardt, A., Matthews, L. E. E., Agil, M., \& Waller, B. M. (2013). Multi component and multimodal lip smacking in crested macaques (Macaca nigra). American Journal of Primatology, 75, 763-773. doi:10.1002/ajp.22105

Morin, E. (1977). La methode. 1. La nature de la nature. Paris: Seuil.

Morrison, H., \& Kuhn, D. (1983). Cognitive aspects of preschoolers' peer imitation in a play situation. Child Development, 54, 1054-1063.

Müller, C. A., Schmitt, K., Barber, A. L. A., \& Huber, L. (2015). Dogs can discriminate emotional expressions of human faces. Current Biology, 25, 1-5. doi:10.1016/j.cub.2014.12.055

Murata, A., Saito, H., Schug, J., Ogawa, K., \& Kameda, T. (2016). Spontaneous facial mimicry is enhanced by the goal of inferring emotional states: evidence for moderation of "automatic" mimicry by higher cognitive processes. PloS ONE, 11, article number: e0153128. doi: 10.1371/journal.pone.0153128

Myowa-Yamakoshi, M., Tomonaga, M., Tanaka, M., \& Matsuzawa, T. (2004). Imitation in neonatal chimpanzees (Pan troglodytes). Developmental Science, 7, 437-442. doi:10.1111/j.1467-7687. 2004.00364.x

Nagell, K., Olguin, R. S., \& Tomasello, M. (1993). Processes of social learning in the tool use of chimpanzees (Pan troglodytes) and human children (Homo sapiens). Journal of Comparative.

Norscia, I., \& Palagi, E. (2011). Yawn contagion and empathy in Homo sapiens. PloS ONE, 6, article number: e28472. doi:10.1371/journal. pone.0028472

Nunes, S., Muecke, E. M., Sanchez, Z., Hoffmeier, R. R., \& Lancaster, L. T. (2004). Play behavior and motor development in juvenile Belding's ground squirrels (Spermophilus beldingi). Behavioral Ecology and Sociobiology, 56, 97-105. doi:10.1007/s00265-0040765-x

Palagi, E. (2006). Social play in bonobos (Pan paniscus) and chimpanzees (Pan troglodytes): Implications for natural social systems and interindividual relationships. American Journal of Physical Anthropology, 129, 418-426. doi:10.1002/ajpa.20289

Palagi, E. (2008). Sharing the motivation to play: The use of signals in adult bonobos. Animal Behaviour, 75, 887-896. doi:10.1016/j. anbehav.2007.07.016

Palagi, E., Antonacci, D., \& Cordoni, G. (2007). Fine-tuning of social play in juvenile lowland gorillas (Gorilla gorilla gorilla). Developmental Psychobiology, 49, 433-445. doi:10.1002/dev. 20219

Palagi, E., Leone, A., Mancini, G., \& Ferrari, P. F. (2009). Contagious yawning in gelada baboons as a possible expression of empathy. Proceedings of the National Academy of Sciences of the United States of America, 106, 19262-19267. doi:10.1073/pnas. 0910891106

Palagi, E., \& Mancini, G. (2011). Playing with the face: playful facial "chattering" and signal modulation in a monkey species
(Theropithecus gelada). Journal of Comparative Psychology, 125, 11-21. doi:10.1037/a0020869

Palagi, E., Nicotra, V., \& Cordoni, G. (2015). Rapid mimicry and emotional contagion in domestic dogs. Royal Society Open Science, 2, 150505. doi:10.1098/rsos. 150505

Palagi, E., Burghardt, G. M., Smuts, B., Cordoni, G., Dall'Olio, S., Fouts, H. N., . . Pellis S. M. (2016). Rough-and-tumble play as a window on animal communication. Biological Reviews, 91, 311-327. doi: $10.1111 /$ brv. 12172

Palagi, E., Cordoni, G., Demuru, E., \& Bekoff, M. (2016). Fair play and its connection with social tolerance, reciprocity and the ethology of peace. Behaviour, 153, 1195-1216. doi:10.1163/1568539X00003336

Pallante, V., Stanyon, R., \& Palagi, E. (2016). Agonistic support towards victims buffers aggression in geladas (Theropithecus gelada). Behaviour, 153, 1217-1243. doi:10.1163/1568539X-00003369

Parr, L. A., Waller, B. M., \& Fugate, J. (2005). Emotional communication in primates: Implications for neurobiology. Current Opinion in Neurobiology, 15, 716-720. doi:10.1016/j.conb.2005.10.017

Pellegrini, A. D. (2009). The role of play in human development. New York: Oxford University Press.

Pellegrini, A. D. (2011). The Oxford handbook of the development of play. New York, USA: Oxford University Press.

Petit, O., Bertrand, F., \& Thierry, B. (2008). Social play in crested and Japanese macaques: Testing the covariation hypothesis. Developmental Psychobiology, 50, 399-407. doi:10.1002/dev. 20305

Power, T. G. (2000). Play and exploration in children and animals. Mahwah: L. Erlbaum.

Preston, S. D., \& deWaal, F. B. M. (2002). Empathy: its ultimate and proximate bases. Behavioral and Brain Sciences, 25, 1-71. doi:10. 1017/S0140525X02000018

Preuschoft, S. (2004). Power and communication. In B. Thierry, M. Singh, \& W. Kaumanns (Eds.), Macaque societies: A model for the study of social organization (pp. 56-60). Cambridge: Cambridge University Press.

Provine, R. R. (2013). Laughing, grooming, and pub science. Trends in Cognitive Sciences, 17, 9-10. doi:10.1016/j.tics.2012.11.001

Quaranta, A., Siniscalchi, M., \& Vallortigara, G. (2007). Asymmetric tail wagging responses by dogs to different emotive stimuli. Current Biology, 17, R199-R201. doi:10.1016/j.cub.2007.02.008

Ray, E., \& Heyes, C. (2011). Imitation in infancy: The wealth of the stimulus. Developmental Science, 14, 92-105. doi:10.1111/j.14677687.2010.00961.x

Reinhart, C. J., Pellis, V. C., Thierry, B., Gauthier, C. A., VanderLaan, D. P., Vasey, P. L., \& Pellis, S. M. (2010). Targets and tactics of play fighting: Competitive versus cooperative styles of play in Japanese and Tonkean macaques. International Journal of Comparative Psychology, 23, 166-200.

Rizzolatti, G., Fadiga, L., Gallese, V., \& Fogassi, L. (1996). Premotor cortex and the recognition of motor actions. Cognitive Brain Research, 3, 131-141. doi:10.1016/0926-6410(95)00038-0

Rizzolatti, G., Fadiga, L., Matelli, M., Bettinardi, V., Paulesu, E., Perani, D., \& Fazio, F. (1996). Localization of grasp representations in humans by PET: 1. Observation versus execution. Experimental Brain Research, 111, 246-252. doi:10.1007/BF00227301

Rooney, N. J., Bradshaw, J. W. S., \& Robinson, I. H. (2001). Do dogs respond to play signals given by humans? Animal Behaviour, 61 , 715-722. doi:10.1006/anbe.2000.1661

Scopa, C., \& Palagi, E. (2016). Mimic me while playing! Social tolerance and rapid facial mimicry in macaques (Macaca tonkeana and Macaca fuscata). Journal of Comparative Psychology, 130, 153161. doi: $10.1037 /$ com0000028

Seibt, B., Mühlberger, A., Likowski, K. U., \& Weyers, P. (2015). Facial mimicry in its social setting. Frontiers in Psychology, 6, 1122. doi: 10.3389/fpsyg.2015.01122 
Smuts, B. (2014). Social behavior among companion dogs with an emphasis on play. In J. Kaminski, \& S. Marshall-Pescini (Eds.), The social dog: Behavior and cognition (pp. 105-130).

Stepper, S., \& Strack, F. (1993). Proprioceptive determinants of emotional and non emotional feelings. Journal of Personality and Social Psychology, 64, 211. doi:10.1037/0022-3514.64.2.211

Stern, D. N. (1985). The interpersonal world of the infant. A view from psychoanalysis and developmental psychology. New York: Basic Books.

Thelen, E., \& Smith, L. B. (1994). A dynamic systems approach to the development of cognition and action. Cambridge: Bradford Books/ MIT Press.

Thierry, B. (1985). Patterns of agonistic interactions in three species of macaque (Macaca mulatta, M. fascicularis, M. tonkeana). Aggressive Behavior, 11, 223-233.

Thierry, B. (2000). Covariation of conflict management patterns across macaque species. In F. Aureli \& F. B. M. de Waal (Eds.), Natural conflict resolution (pp. 106-128). Berkeley: University of California Press.

Thierry, B. (2004). Social epigenesis. In B. Thierry, M. Singh, \& W. Kaufmanns (Eds.), Macaque societies: A model for the study of social organization (pp. 267-290). Cambridge: Cambridge University Press.

Thierry, B. (2007). Unity in diversity: Lessons from macaque societies. Evolutionary Anthropology, 16, 224-238. doi:10.1002/evan.20147

Thorpe, W. H. (1963). Learning and instinct in animals (2nd ed.). Cambridge: Harvard University Press.

Tinbergen, N. (1963). On aims and methods of ethology. Ethology, 20, $410-433$.
Tomasello, M., Kruger, A. C., \& Ratner, H. H. (1993). Cultural learning. Behavioral and Brain Sciences, 16, 495-511. doi:10.1017/ S0140525X0003123X

Tomasello, M., \& Call, J. (1997). Primate cognition. New York Oxford: Oxford University Press.

Trevarthen, C., \& Aitken, K. J. (2001). Infant intersubjectivity: Research, theory, and clinical applications. Journal of Child Psychology and Psychiatry, 42, 3-48. doi:10.1111/1469-7610.00701

van Hooff, J. A. R. A. M. (1972). A comparative approach to the phylogeny of laughter and smiling. In R. A. Hinde (Ed.), Nonverbal communication (pp. 209-241). Cambridge, UK: Cambridge University Press.

van Hooff, J. A. R. A. M. (1989). Laughter and humor, and the "duoinduo" of nature and culture. In A. K. Walter (Ed.), The nature of culture (pp. 120-149). Bochum: Brockmeyer.

van Hooff, J. A. R. A. M., \& Preuschoft, S. (2003). Laughter and smiling: The intertwining of nature and culture. In F. B. M. de Waal \& P. L. Tyack (Eds.), Animal social complexity (pp. 260-287). Cambridge: Harvard University Press.

Waller, B. M., \& Dunbar, R. I. (2005). Differential behavioural effects of silent bared teeth display and relaxed open mouth display in chimpanzees (Pan troglodytes). Ethology, 111, 129-142. doi:10.1111/j. 1439-0310.2004.01045.x

Whiten, A., McGuigan, N., Marshall-Pescini, S., \& Hopper, L. M. (2009). Emulation, imitation, over-imitation and the scope of culture for child and chimpanzee. Philosophical Transactions of the Roval Society of London B: Biological Sciences, 364, 2417-2428. doi:10. 1098/rstb.2009.0069 